\title{
Effective Use of Transfer Plates in Mixed Development
}

\author{
K.M.K. Bandara, S.S. Bandara and M.T.R. Jayasinghe
}

\begin{abstract}
The need for providing car parking within apartment buildings often lead to a situation where different grid arrangements exist in the parking and apartment floors. In most cases, a setback is also present to accommodate this change over. This requires the use of a transfer system such as a transfer plate or transfer beams. In mixed development, there is a possibility to change the location of the transfer floor. This paper explores the added advantage of using a transfer plate in such situations due to its outrigger behaviour and how it changes when its location is changed. A case study of a highrise apartment building is used to demonstrate different trends in outrigger behaviour with respect to dynamic wind and earthquake loading.
\end{abstract}

Keywords: Transfer plate, setback, P-delta effects, dynamic analysis, earthquakes

\section{Introduction}

With the rapid growth of urban development, high-rise buildings are constructed at an increasing rate. Many apartment buildings are among them, due to high land values in residential areas. In most cases, these apartment buildings will have car parking at the lower floors. Often different grid arrangements exist in the parking and apartment floors that result in the need for setbacks and transfer systems. It should be noted that the transfer plate is generally located at the level of the setback, integrating the behaviour of the two components. It is known that thick plates can be used as transfer plates with an additional advantage of them behaving as outriggers [Balasuriya et al., 2007]. With the popularity of mixed development, most apartment buildings tend to have shopping centers and various other facilities within the same building. With this recent development, the designer may have the flexibility to change the location of the transfer plate, affecting its outrigger behaviour. This paper mainly focuses on how transfer plates can be used effectively in mixed development. The behaviour of a transfer plate is investigated using Three Dimensional Finite Element modelling and its outrigger action is studied by taking into account the different loading conditions such as earthquake and dynamic behaviour under wind conditions, etc.

\section{Objective}

Themainobjectiveistoinvestigate theadvantages and disadvantages of changing transfer floor location in a mixed development with respect to the outrigger behaviour of the transfer plate and show how a compromising solution can be obtained with respect to keeping both wind and earthquake response to a minimum.

\section{Methodology}

A case study of a mixed development project with the transfer floor at different levels is used to study its outrigger behaviour with respect to wind and earthquake induced dynamic conditions. A thick plate is used as the transfer structure while a setback is also present at the same level. The difference in behaviour of the structure in terms of wind and earthquake response for Sri Lankan conditions is explored. An attempt is then made to find an optimum level for location of the transfer floor while keeping wind and earthquake response in acceptable ranges. Later, the influence of the setback on the overall outrigger behaviour of the structure is studied to highlight the dominance of the transfer plate.

A 29 storey apartment building with a single set back is selected as the case study (Figures 1 and 2) with both apartment and parking levels, which is to be provided with a transfer floor at the set back level. Finite element modelling is carried out using the commercial package, SAP2000 [SAP2000 Analysis reference, 2002].

K.M.K. Bandara, B.Sc. Eng (Moratnua), Research Assistant, Department of Civil Engineering, Unize rsity of Moratutua.

S.S. Bandara, B.Sc. Eng (Moratuwa), Lecturer, Department of Civil Engineering, University of Moratutwa.

Eng. (Prof.) M.T.R. Jayasinghe, B.Sc. Eng (Moratuwa), Ph..D. (Cambridge), C.Eng., MIE(Sri Lanka), ,Professor, Department of Civil Engineering, University of Moratuwa. 

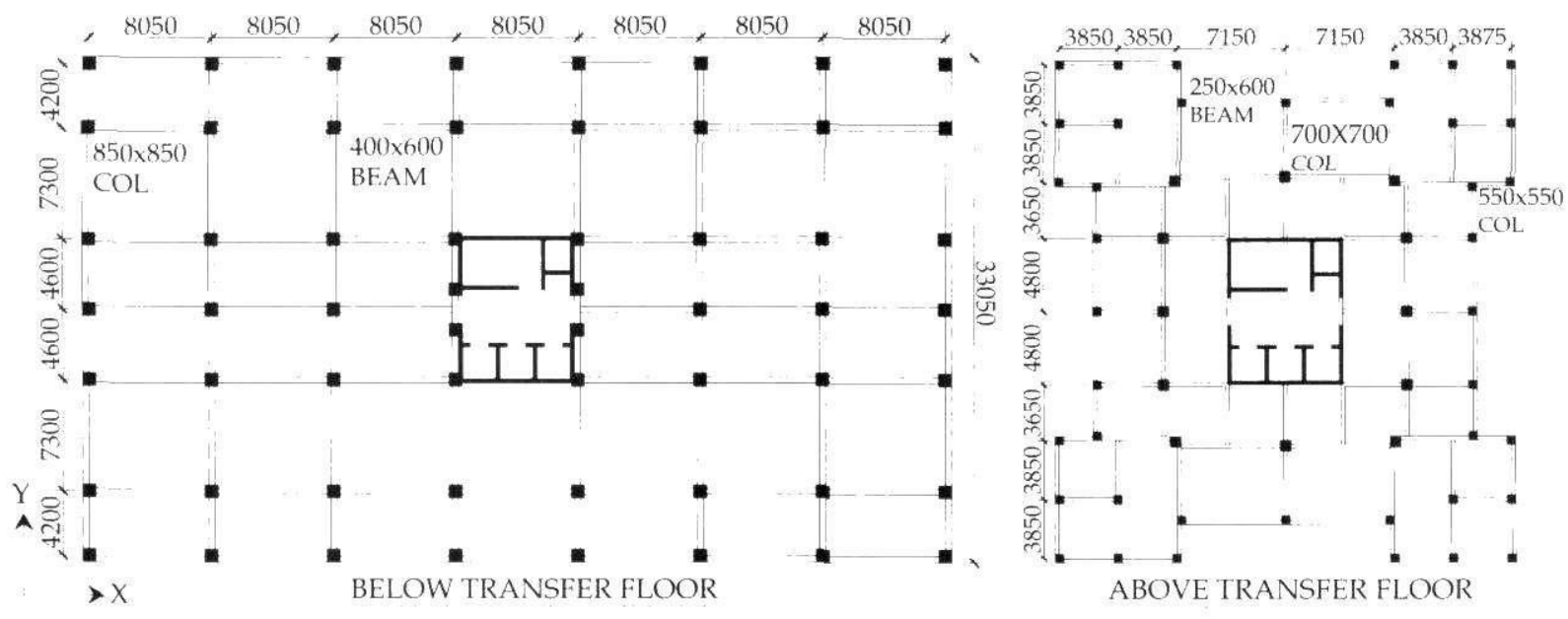

Figure 1 - Plan views of the building used as the case study (dimensions in $\mathrm{mm}$ )

Several models are used in order to take account of mixed development with transfer floor levels at $4^{\text {th }}, 6^{\text {th }}, 8^{\text {th }}, 10^{\text {th }}$, and $16^{\text {th }}$. A $1.0 \mathrm{~m}$ thick transfer plate is used in all models for the sake of comparison. Additional models are created to study the following cases:

1) Having the transfer plate without a setback

2) Having neither the transfer nor the setback

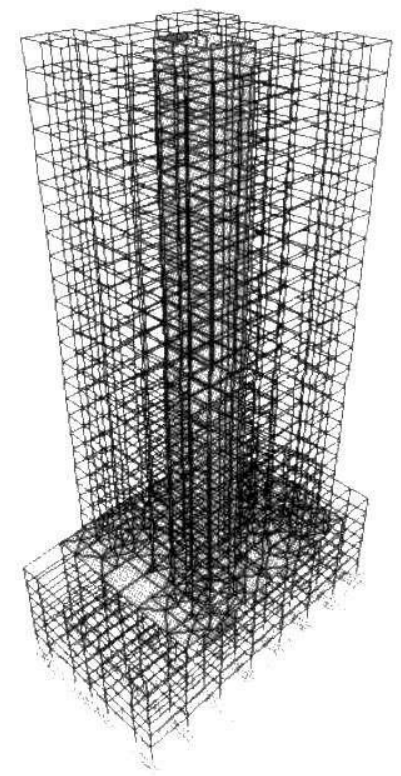

Figure 2 - Three dimensional model of building with transfer plate and setback

All models have the same overall building height of $104.2 \mathrm{~m}$.

\section{Model definition}

Since dynamic analysis is to be performed, estimating the correct mass of the structure is of utmost importance. In addition to element self weight, mass from finishes, services, partition walls, etc. are considered along with mass from $40 \%$ of the live load. This particular percentage of live load mass participation is that recommended in AS1170.1-1989 for earthquake analysis.

The wind load analysis is carried out based on loads evaluated from AS1170.2-1989 (with a basic wind speed of $33 \mathrm{~m} / \mathrm{s}$ to suit Sri Lankan conditions). The dynamic response to wind is obtained by multiplying static wind response by the gust factor. Calculations for the wind load are included in Appendix A.1.

The chances for the reinforced concrete members to crack under working loads and wind induced loads were considered for the wind analysis since they are more critical. Initial $E$ value of concrete is reduced by $80 \%$ to account for the effect of sustained loading. Gross value of second moment of area, I, for beams and columns, respectively, are reduced by 0.5 and 0.8 to allow for cracking [Smith \& Coull, 1991].

Static and dynamic earthquake analyses have been performed using AS 1170.4-1993 for a ground acceleration of $0.15 \mathrm{~g}$ which can be generally recommended for a country with low incidence of earthquakes. Static base shear values are calculated using the natural periods of vibration (Eigen vector analysis).

The calculation of static base shear is given in Appendix A.2. It is seen from Figure 3 that lesser periods are subject to higher spectral accelerations. Thus, short term conditions have been used for properties such as elastic modulus during the earthquake analysis as it yields lesser natural periods, and hence greater base shear values. 


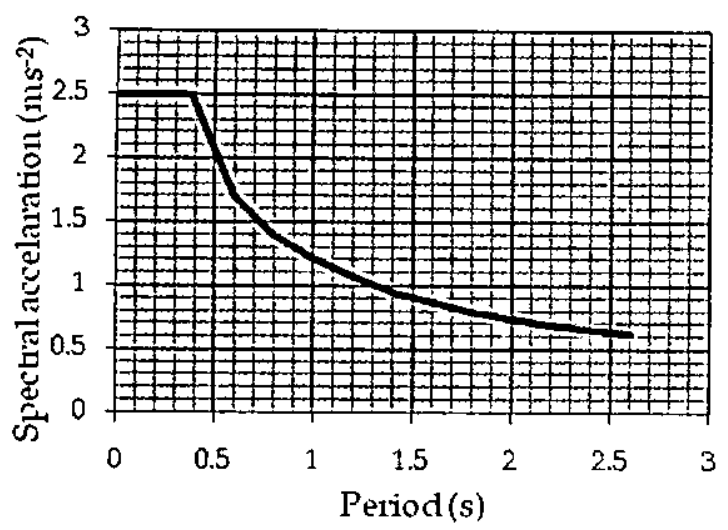

Figure 3 - Spectral Acceleration Vs Period

Dynamic analysis uses the Response spectrum method with the normalized response spectra obtained from AS 1170.4-1993 for a site factor of 1.0 (Figure 3 ). It is now recongnized that loaddependent Ritz vectors produce more accurate results when used for a seismic dynamic analysis than if the exact free-vibration mode shapes (Eigen vector analysis) are used [Wilson, 1995]. However both Eigen and Ritz vector methods resulted in mass participations of more than $80 \%$ (The minimum requirement specified in AS1170.2 -1989). Therefore, both methods are used during dynamic analysis. Due to the layout of the building, wind loads are critical for the $y$ direction. However such a prediction cannot be made regarding earthquake analysis which implies that both directions must be considered. The different earthquake analysis cases used are explained in Table 1.

Table 1 - Earthquake analysis cases

\begin{tabular}{|c|c|c|c|}
\hline Case & $\begin{array}{c}\text { Direction of } \\
\text { ground } \\
\text { acceleration }\end{array}$ & $\begin{array}{c}\text { Dynamic } \\
\text { or static }\end{array}$ & $\begin{array}{c}\text { Modal type } \\
\text { used if analysis } \\
\text { is dynamic }\end{array}$ \\
\hline A & $\mathrm{x}$ & Static & N/A \\
\hline B & $\mathrm{y}$ & Static & N/A \\
\hline C & $\mathrm{x}$ & Dynamic & Eigen vector \\
\hline D & $\mathrm{y}$ & Dynamic & Eigen vector \\
\hline E & $\mathrm{x}$ & Dynamic & Ritz vector \\
\hline F & $\mathrm{y}$ & Dynamic & Ritz vector \\
\hline
\end{tabular}

\section{Effects of wind loading}

Figure 4 shows the variation of average drift at each floor level at and below the transfer plate level for all models. These values are obtained averaging all the joint displacements at the respective floor level. From these results, it seems that up to the transfer plate (TP) level, response to wind becomes more severe when the transfer plate is located at a higher level. However when considering the whole building as in Figure 5, the top deflection reduces as the transfer plate is located higher in the structure. There is a change in slope in every graph at the transfer plate level when closely inspected. In both Figures 4 and 5 , the model without the transfer plate displays the maximum drift of all models. Figure 6 shows the deflected shape of all models ( $y-z$ plane). The change in curvature of the building at transfer floor level is clearly visible in it.

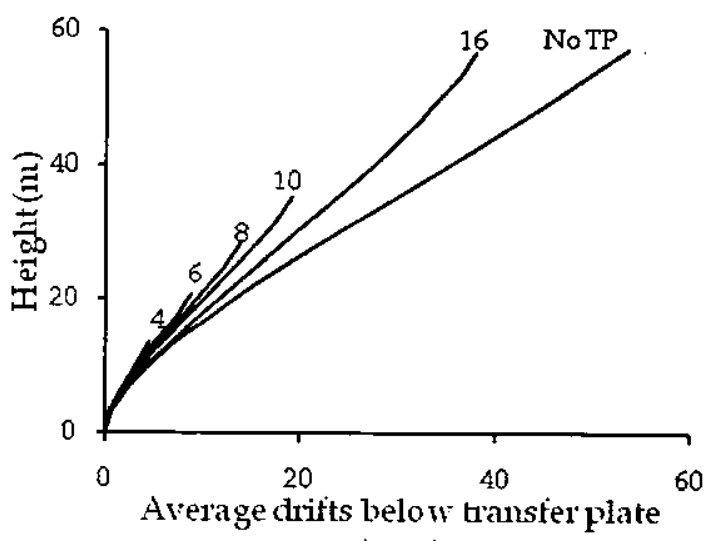

(min)

Figure 4 - Average drifts below transfer plate

Table 2 shows the drift index and maximum inter storey drift with the relevant floor. Acceptable zone for drift index is 0.001-0.005 [Smith \& Coull, 1991]. The fact that drift values for all models are below the lower limit of this zone imply that deflections are low for this particular structure.

Nevertheless, the drift index and maximum inter storey drift reduces as the transfer plate is moved higher up. The model without any transfer plate has the maximum values.

The next important criterion by which to evaluate the building is considering human comfort. Comfort limits can be expressed in terms of displacement amplitude, acceleration and period of vibration. It is evident from Figure 7 that while reductions in acceleration and displacement amplitude are beneficial in improving human comfort, the opposite is true for vibration period. Figure 8 shows that the allowable displacements for different comfort zones (corresponding to the periods of vibrations of models) as derived from Figure 7. 


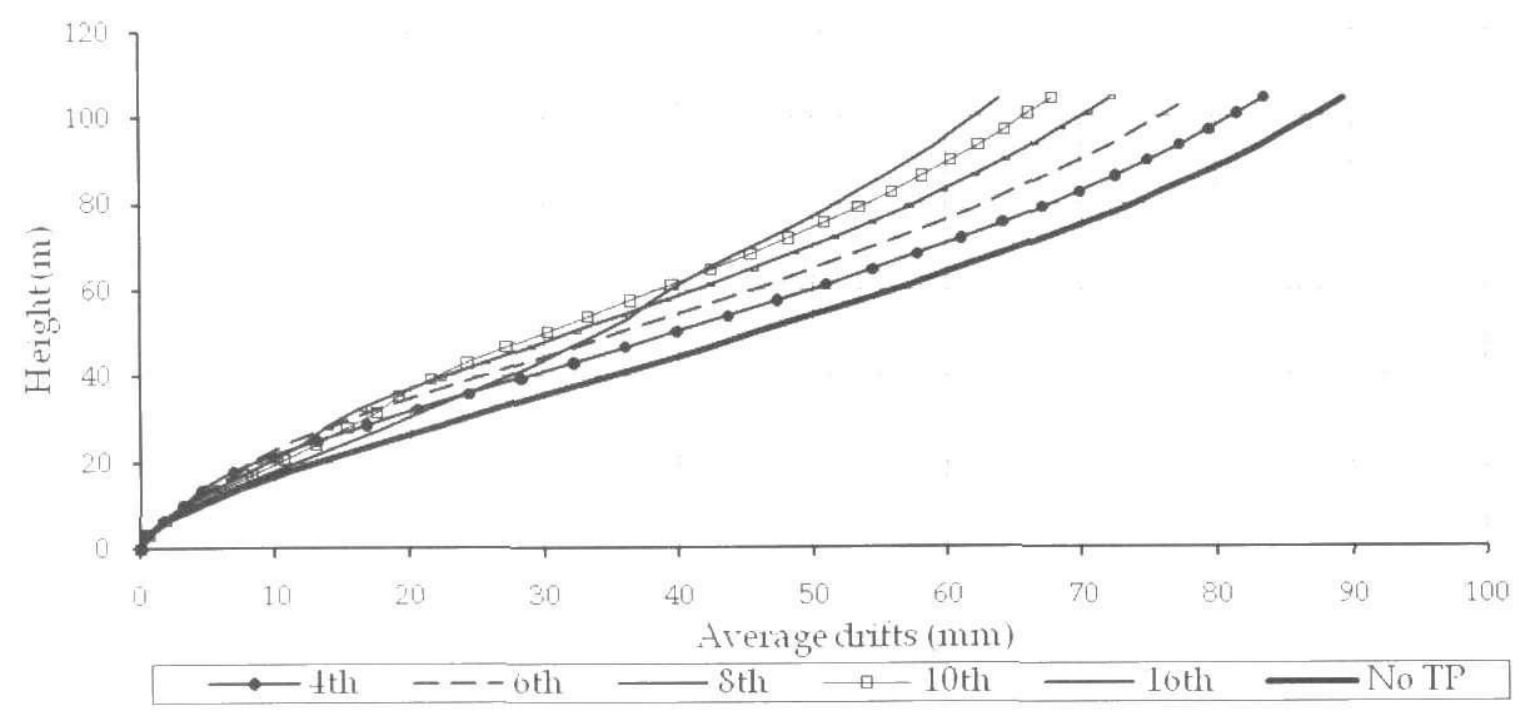

Figure 5 - Average drifts for the whole building

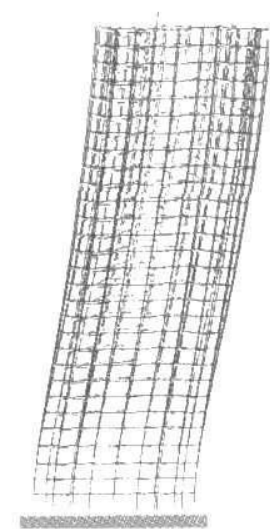

No TP

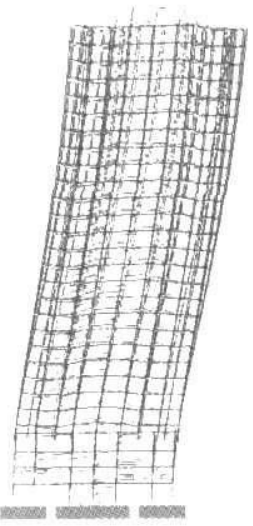

TP at $4^{\text {th }}$

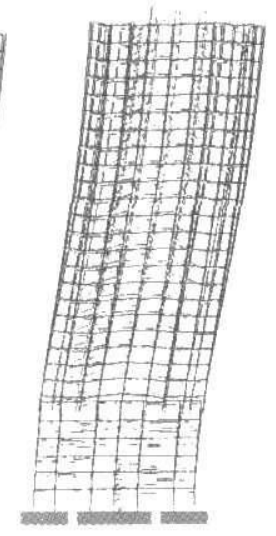

TP at $6^{\text {th }}$

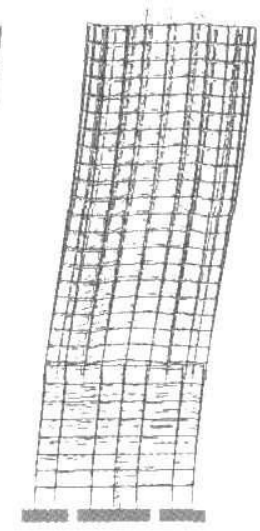

TP at $8^{\text {th }}$

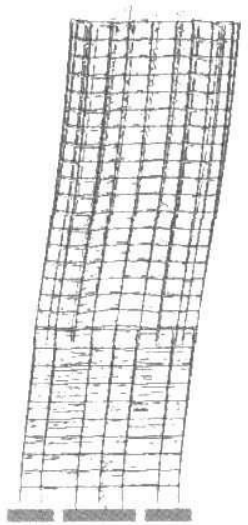

TP at $10^{\text {th }}$

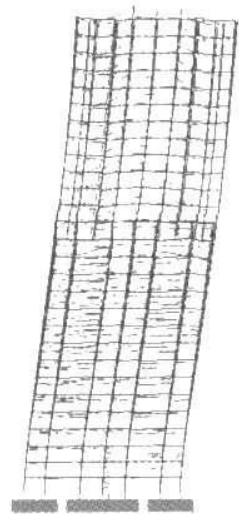

TP at $16^{\text {th }}$

Figure 6 - Deflected shapes (yz plane)

This leads to the observation that no improvement to human comfort has been achieved by either changing the transfer plate location or having a transfer plate in the first place (Figure 8).

Table 2 - Inter storey drift and drift index

\begin{tabular}{|c|c|c|c|}
\hline \multirow{2}{*}{$\begin{array}{c}\text { Transfer } \\
\text { floor } \\
\text { level }\end{array}$} & \multicolumn{2}{|c|}{$\begin{array}{l}\text { Max. inter storey } \\
\text { drift }\end{array}$} & \multirow{2}{*}{$\begin{array}{c}\text { Drift index } \\
\text { (Max top Dis. } \\
\text { / building } \\
\text { height) }\end{array}$} \\
\hline & $\begin{array}{c}\text { Location } \\
\text { of max } \\
\text { drift }\end{array}$ & drift & \\
\hline No T.P. & 11 & 0.00111 & 0.00086 \\
\hline 4 & 12 & 0.00108 & 0.00080 \\
\hline 6 & 14 & 0.00102 & 0.00075 \\
\hline 8 & 16 & 0.00094 & 0.00069 \\
\hline 10 & 17 & 0.00086 & 0.00065 \\
\hline 16 & 8 & 0.00080 & 0.00061 \\
\hline
\end{tabular}

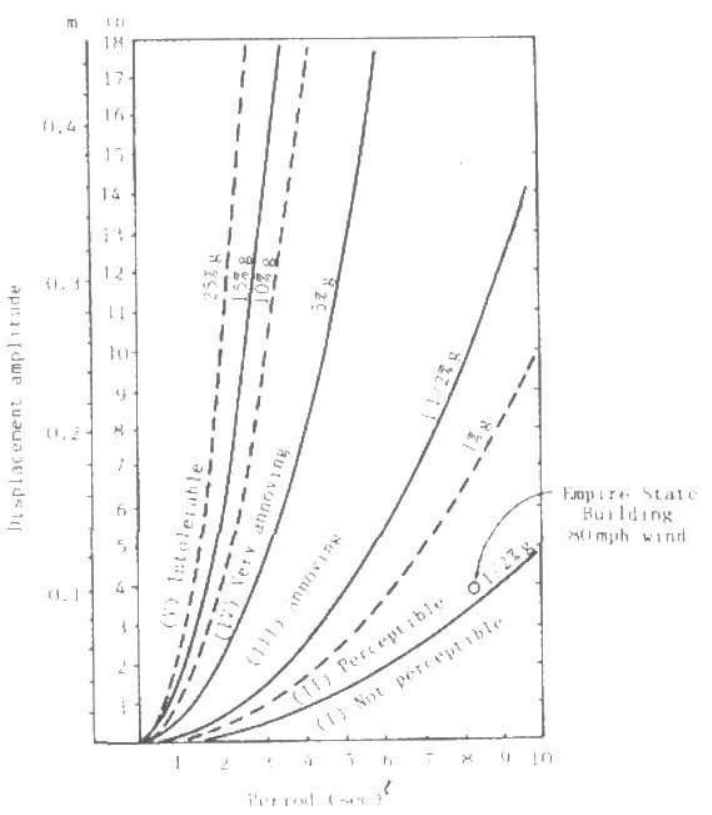

Figure 7 - Human comfort curves [Chang, 1973] 


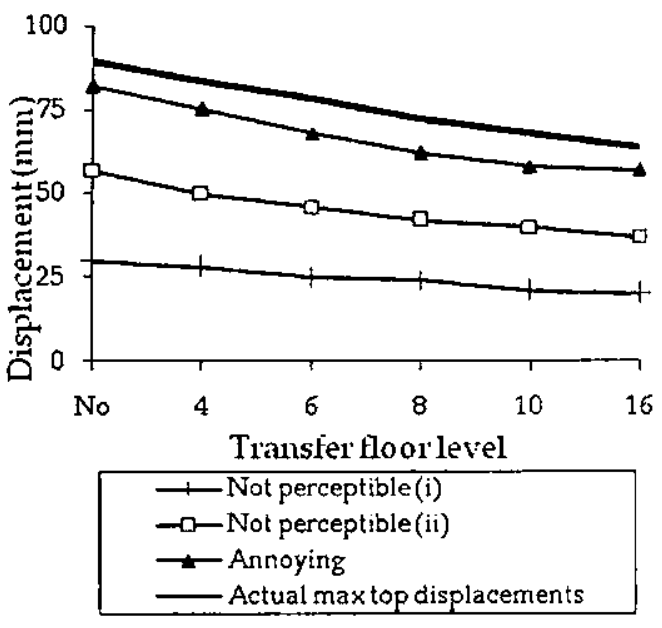

Figure 8 - Variation of displacements for comfort zones

However, it is now generally agreed that acceleration is a predominant parameter in determining the nature of human response to vibration [Irwin, 1986].

It should be noted that the above trends have been determined for a basic wind speed of 33 $\mathrm{m} / \mathrm{s}$. However, in practice, generally a lower speed such as $20-25 \mathrm{~m} / \mathrm{s}$ can be used in Sri Lanka since wind induced accelerations may have a lower return period (5-10 years) than that used for structural design calculations (50 years). Nevertheless, the trends that are predicted with $33 \mathrm{~m} / \mathrm{s}$ basic wind speed will yet be applicable since the structure is expected to behave in the elastic range and SAP 2000 results are also based on an elastic analysis.

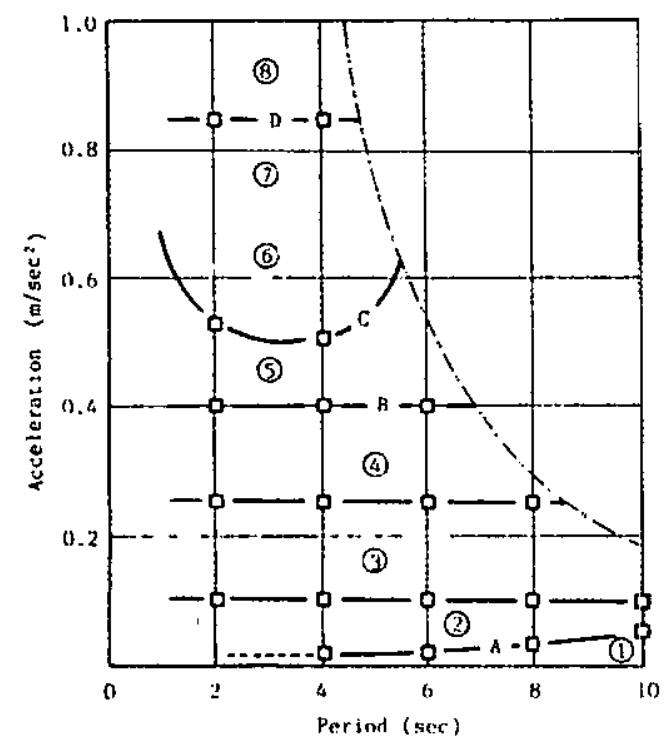

Figure 9 - Building motion criteria for hurnan response [Yamada \& Goto, 1975].
Figure 9 demonstrates how only acceleration and not natural period affects the human comfort range of a building particularly for ranges 1-5 (Table 4).

Table 3 shows periods of vibrations and respective along wind accelerations calculated according to AS 1170.2 - 1989 (See Appendix A.1 for the calculations).

Placing these values in Figure 9 and Table 4 reveal that although all models fall in the range where majority of people will perceive motion, the degree of severity reduces when the transfer plate is located higher up. Again the model without transfer plate has the highest acceleration thus is the most severe. Even the small reduction in acceleration that can be achieved in apartment buildings would be important as people live in them.

Table 3 - Periods of vibrations and accelerations for wind analysis

\begin{tabular}{|c|c|c|}
\hline $\begin{array}{c}\text { Transfer floor } \\
\text { level }\end{array}$ & T1 (s) & $\begin{array}{c}\text { Acceleration } \\
\left(\mathrm{m} / \mathrm{s}^{2}\right)\end{array}$ \\
\hline No TP & 4.4422 & 0.1938 \\
\hline $4^{\text {th }}$ & 4.2429 & 0.1905 \\
\hline $6^{\text {th }}$ & 4.0805 & 0.1858 \\
\hline $8^{\text {th }}$ & 3.9357 & 0.1784 \\
\hline $10^{\text {th }}$ & 3.8149 & 0.1736 \\
\hline $16^{\text {th }}$ & 3.6602 & 0.1710 \\
\hline
\end{tabular}

Table 4 - Human perception levels (With reference to Figure 9)

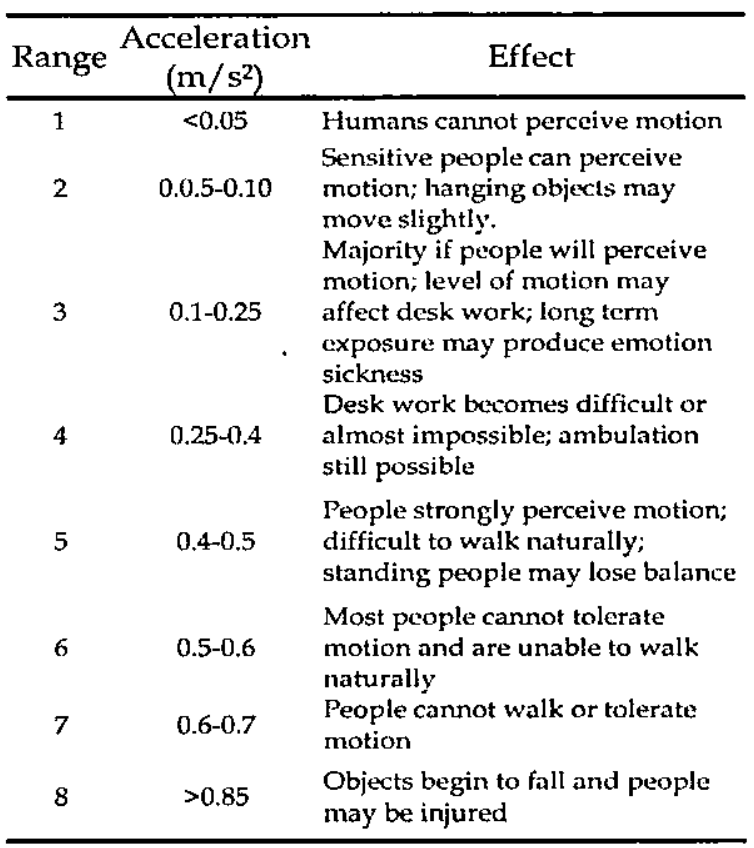


SAP2000 generally gives base overturning moments with respect to $(0,0)$ coordinates which may lead to inaccurate comparisons (Contribution from eccentricity of vertical loads). Therefore, base overturning moments are obtained (Table 5) with respect to the load centroid of vertical loads from $1.0 \mathrm{gk}+0.4 \mathrm{qk}$ load case. Both base shear and base overturning moments are higher for models where the transfer plate is located higher up as the surface area of the building exposed to wind increases (Due to the difference in building width above and below transfer plate).

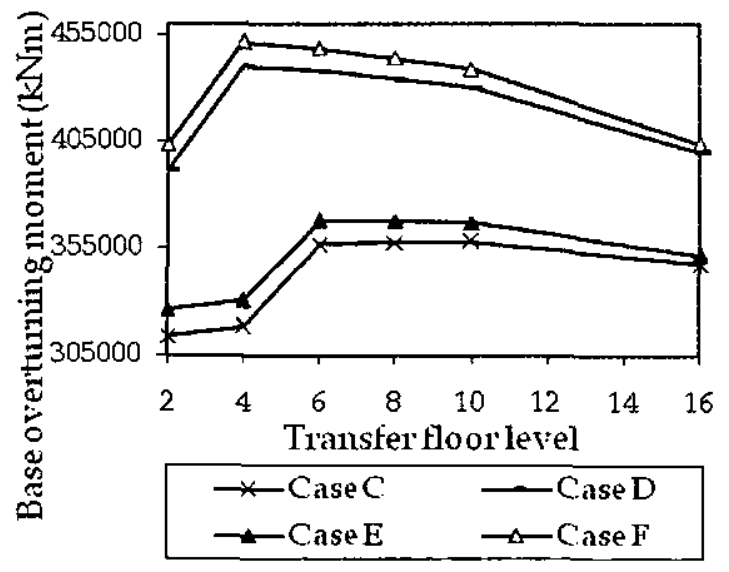

Figure 10 - Variation of base overturning moment for dynamic earthquake analysis

\section{Effects of earthquake loading}

Figures 10 and 11 show the variation of base overturning moment and base shear, respectively, for static and dynamic earthquake analysis. It should be noted that Ritz vector analysis has given higher response with respect to both base shear and base overturning moment for the cases highlighted in Table 1.

The introduction of the transfer plate has resulted in an increase of both parameters but this trend has gradually declined as the transfer plate is moved higher up. The existence of a large mass (the transfer plate) within the structure has resulted in the former observation. The latter can be explained as due to the reduction of periods (Figure 12) that occur as the transfer plate is moved higher up.

As observed with the wind analysis, displacements have reduced (Figure 13) when the transfer plate level is moved up. The pattern is same for both Eigen and Ritz vector analysis.

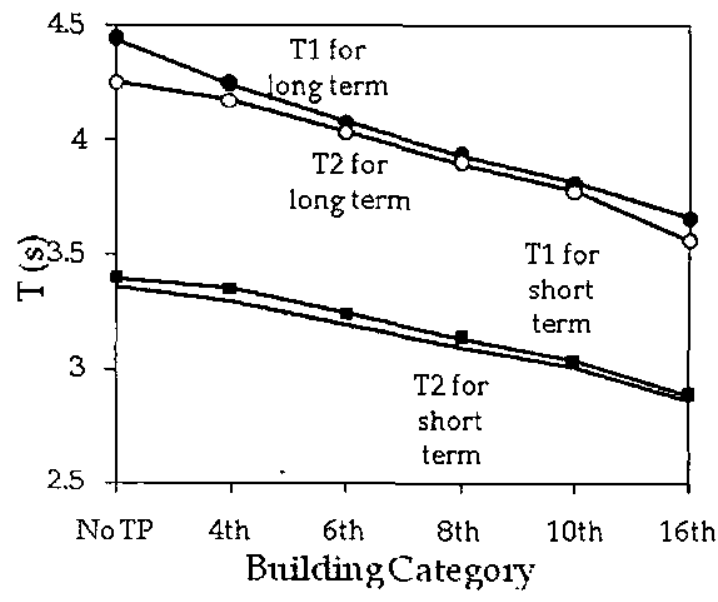

Figure 12 - Variation of periods of vibrations for short term and long term conditions

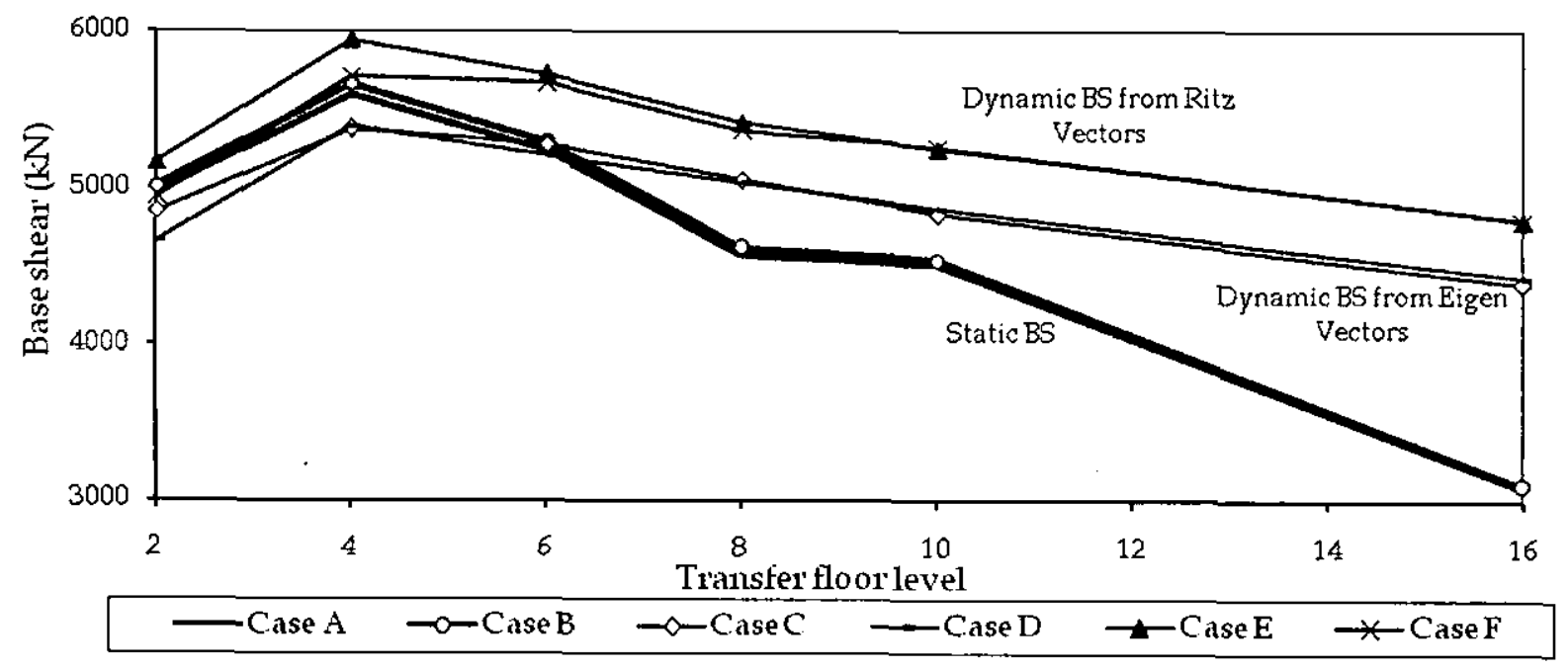

Figure 11 - Variation of base shear values in static and dynamic analysis 
Table 5 - Base shear and base overturning moments

\begin{tabular}{|c|c|c|}
\hline $\begin{array}{c}\text { Transfer } \\
\text { floor } \\
\text { level }\end{array}$ & $\begin{array}{c}\text { Base Shear } \\
\text { Fy }(\mathrm{kN})\end{array}$ & $\begin{array}{c}\text { Base Overturning } \\
\text { Moment }-\mathrm{Mx} \\
(\mathrm{kNm})\end{array}$ \\
\hline No T.P. & 3722 & 156739 \\
\hline 4 & 3896 & 149279 \\
\hline 6 & 4043 & 155773 \\
\hline 8 & 4196 & 164511 \\
\hline 10 & 4372 & 174796 \\
\hline 16 & 5023 & 223685 \\
\hline
\end{tabular}

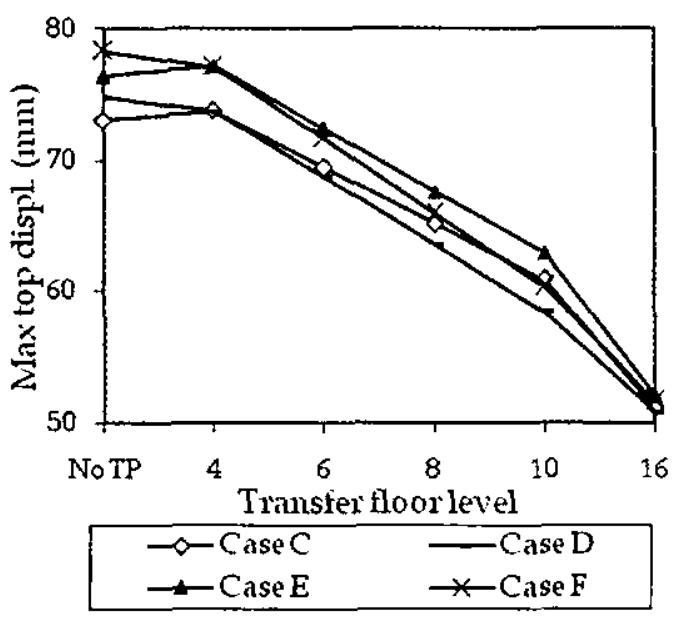

Figure 13 - Variation of maximum top displacement values for dynamic earthquake analysis

\section{Influence of set back}

In all models analysed thus far that contain the transfer plate, the set back is also located at the same level. This is due to architectural requirements as seen in Figure 14.

Most mixed development projects contain such a setback at the transfer level due to similar architectural requirements.
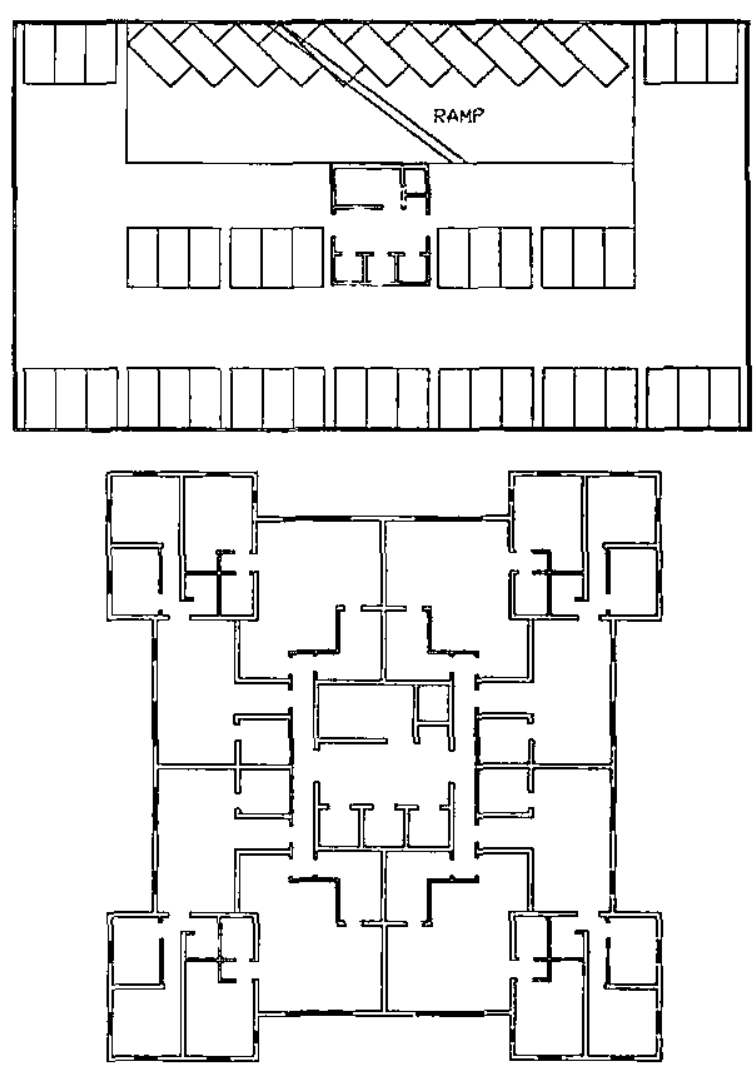

Figure 14 - General architectural drawings for apartment and parking floors

Having a setback at the transfer floor implied that all observations made thus far are influenced by not only the transfer plate, but the set back as well. To study the extent of this influence, the structure is evaluated with a reduced setback (Figure 15) for the two extreme cases (ie transfer floor at level 4 and at level 16).

Table 6 summarises the impact of reducing the setback with respect to the two main lateral stability parameters, namely natural period of vibration and drift index.

Table 6 - Influence of setback on lateral stability

\begin{tabular}{|c|l|c|l|c|c|}
\hline \multirow{2}{*}{$\begin{array}{c}\text { Location of } \\
\text { transfer } \\
\text { plate/setback }\end{array}$} & \multicolumn{1}{|c|}{ Case } & \multirow{2}{*}{$\begin{array}{l}\text { T1 long } \\
\text { term }(\mathrm{s})\end{array}$} & $\begin{array}{l}\text { T1 } \\
\text { short } \\
\text { term } \\
\mathrm{s}\end{array}$ & & \multicolumn{2}{|c|}{ Drift index } \\
\cline { 4 - 6 } & & & & wind & earthquake \\
\hline \multirow{2}{*}{16} & No set back & 3.84 & 3.07 & 0.00063 & 0.00053 \\
\cline { 2 - 6 } & With setback & 3.66 & 2.89 & 0.00061 & 0.00050 \\
\hline \multirow{2}{*}{4} & No set back & 4.27 & 3.37 & 0.00080 & 0.00074 \\
\cline { 2 - 6 } & With setback & 4.24 & 3.36 & 0.00081 & 0.00074 \\
\hline \multicolumn{2}{|c|}{ No transfer plate or set back } & 4.44 & 3.40 & 0.00086 & 0.00075 \\
\hline
\end{tabular}




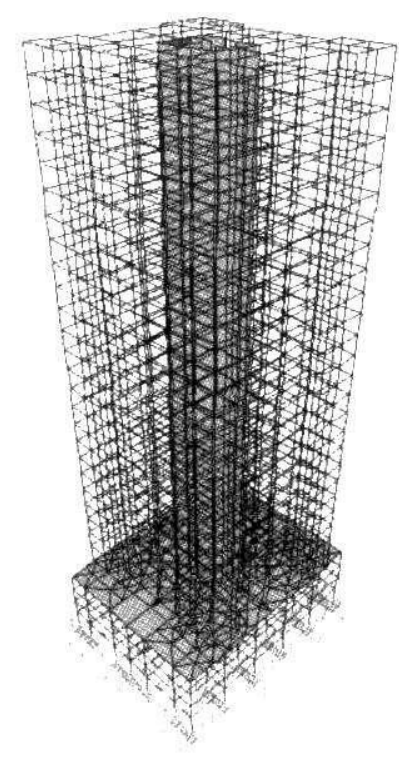

Figure 15- Model with reduced setback

It is evident that removing the setback has slightly reduced lateral stability when the transfer floor is located higher up. However, for the case of it being located at a lower level, the set back has little or no impact as evident from the results. Thus, it can be said that the improved stability by locating the transfer floor higher up to the transfer plate with little influence from the set back.

\section{Summary of results}

Figure 16 shows the summery of wind analysis. The advantage of using a transfer plate at a higher level is clear from it, especially due to the reduction of acceleration. Since human comfort cannot be expected for earthquake scenarios, having the transfer plate at a higher level is clearly favourable in this regard. Also, when considering the variation of maximum top displacement, both displacement curves in Figure 17 have the same trend in favour of having the transfer plate higher up. When it comes to design parameters, base shear and base over turning moment can be used as a measure of transfer plate effectiveness.

The trends of these are different for wind analysis and earthquake analysis (Figures 18 and 19). Base shear values for wind analysis increases when transfer floor level is moved up (due to the difference in building width above and below transfer plate), while earthquake analysis results behave in the opposite manner.

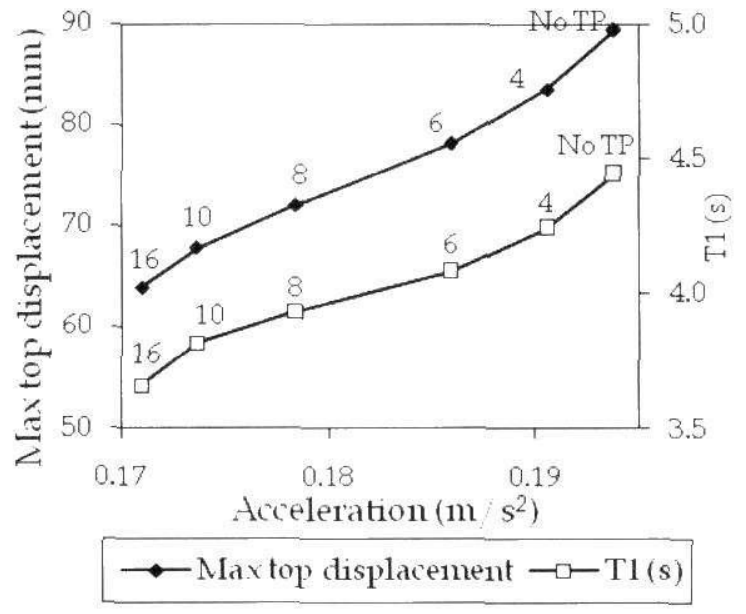

Figure 16 - Variation of max top displacement and period of vibration with respect to acceleration

For earthquake analysis, the increase of both parameters with the introduction of a transfer plate should be noted.

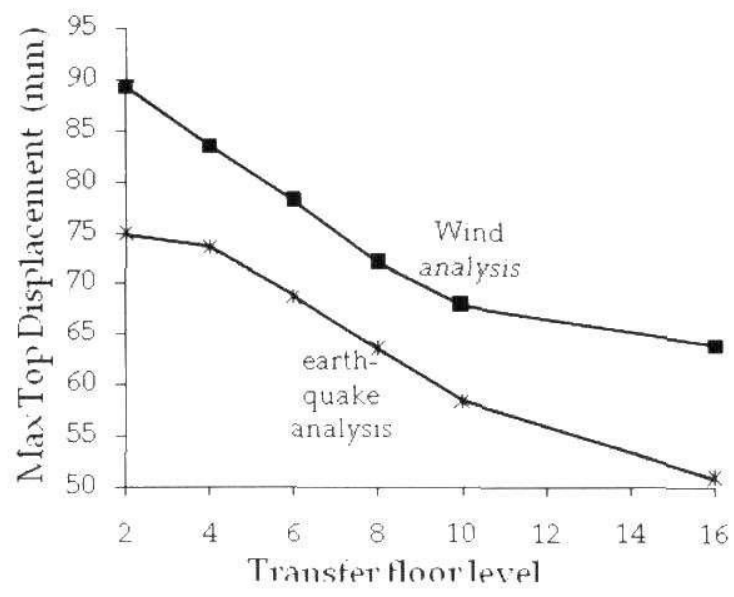

Figure 17 - Variation of maximum top displacement in earthquake and wind analysis (y direction)

\section{Conclusions}

Earthquake and Wind analysis each have different critical parameters that however follow similar trends as transfer plate level is increased. The behaviour of the transfer plate as an outrigger is evident in all results which can be used to an advantage in reducing drift and acceleration. This improves human comfort which is vital for buildings with apartments as people are living in them. The outrigger behaviour of the transfer plate improves as it is located higher up in the building. 


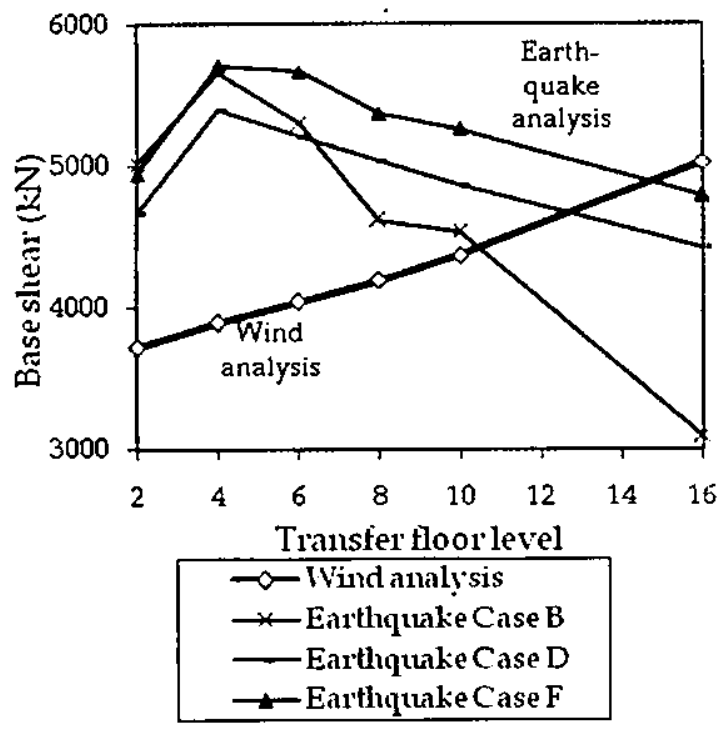

Figure 18 - Variation of base shear in earthquake and wind analysis ( $y$ direction)

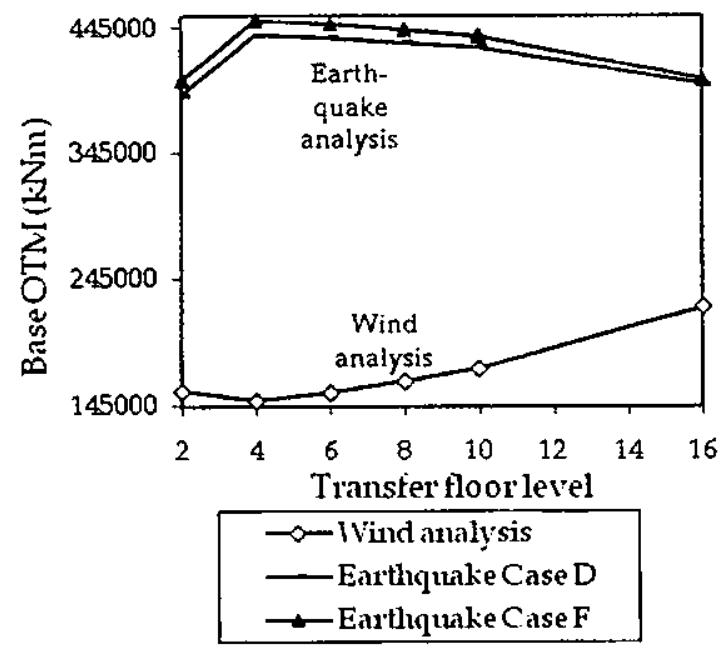

Figure 19 - Variation of base overturning moment in earthquake and wind analysis (y direction)

Having a transfer plate is a disadvantage with respect to earthquake induced base shear and overturning moment. However, this diminishes as the transfer plate is moved higher up. Relative comparison of base shear and overturning moment between wind and earthquake analysis is very much case dependent. Nevertheless, these too can be used to advantage by balancing the wind loaded area above and below transfer plate.

Regarding an optimum location for transfer plate, once the critical upper limit (can be either acceleration, base shear or overturning moment, max top deflection, etc. depending on the dimensions of the building) is established, the trends predicted in this research can be used as a guide to determine the most favourable location. However, it is best to follow the steps described here and obtain the actual trend for the particular building in question. Once the actual trends are found along with the critical lateral stability parameter, the optimum location for the transfer plate can be determined to make best use of its outrigger behaviour.

\section{References}

1. AS1170.1-1989, "Minimum design loads on structures- Part 1: Dead and live loads and load combinations", Standards Australia, New South Wales.

2. AS1170.2-1989, "Minimum design loads on structures- Part 2: Wind loads", Standards Australia, New South Wales.

3. AS1170.4-1989, "Minimum design loads on structures- Part 4: Earthquake loads", Standards Australia, New South Wales.

4. Balasuriya, S.S., Bandara, K.M.K., Ekanayake, S.D., Jayasinghe, M.T.R. (2007), "The influence of transfer plates on the lateral behaviour of apartment buildings, Engineer, Journal of Institution of Engineers, Sri Lanka, Vol: XXXX, No: 4, pp 22-30.

5. Chang, F. K. (1973), "Human Response to Motion in Tall Buildings.", J. Struct. Div., A.S.C.E. 99, pp. 1259-1272.

6. Irwin, A. W. (1986), "Htman Response to Motion in Tall Buildings.", Proc. Conf. on Tall Buildings. Second Century of the Skyscraper, Chicago, 759-778

7. SAP2000 Analysis reference, (2002), Computers and Structures, Inc., Berkeley, Califonia, USA, Version 8.0.

8. Smith, B. S., Coull, A. (1991), "Tall Building Structures", John Wiley, USA, pp. 537.

9. Wilson, L. Edward. (1995), "Three Dimensional Static and Dynamic Analysis of Structures", Computers and structures, Inc., USA,

10. Yamada, M and Goto, T. (1975), "The Criteria to Motions in Tall Buildings", Proc. Pan-Pacific Tall Buildings Conference, Haweii, pp. 233244 


\section{Appendix}

\section{Appendix A.1 Wind analysis}

Calculation of gust factor (G) (According to AS 1170.2 - 1989)

For model where the transfer plate is at $4^{\text {th }}$ level considering long term effects

Basic wind speed $(\mathrm{V})$

Height of the building (h)

$=33.0 \mathrm{~m} / \mathrm{s}$ $=104.2 \mathrm{~m}$

Computed fundamental period of $=4.24 \mathrm{~s}$ vibration of the building

Estimated natural frequency $\left(\mathrm{n}_{\mathrm{v}}\right) \quad=0.236 \mathrm{~Hz}$

Clause 4.4.2.

$$
\begin{aligned}
& G=1+r \sqrt{\left[g_{v}^{2} B(1+w)^{2}+\frac{g_{f}^{2} S E}{\zeta}\right]} \\
& \mathrm{r}=\frac{2\left(\frac{\sigma_{v}}{\bar{V}}\right)}{\bar{M}_{t}}=\frac{2 \times 0.166}{1.0}=0.332 \\
& g_{v}=3.7 \\
& g_{\mathrm{f}}=\sqrt{2 \log _{\mathrm{e}}\left(3600 \mathrm{n}_{\mathrm{a}}\right)} \\
& =\sqrt{2 \log _{\mathrm{e}}(3600 \times 0.24)}=3.67 \\
& \overline{\mathrm{V}}_{\mathrm{h}}=\mathrm{V} \overline{\mathrm{M}}_{(\mathrm{h} \text { (at) }} \mathrm{M}_{\mathrm{s}} \overline{\mathrm{M}}_{\mathrm{t}} \mathrm{M}_{\mathrm{i}} \\
& =33.0 \times 0.72 \times 1.0 \times 1.0 \times 1.0=23.76 \mathrm{~m} / \mathrm{s} \\
& \mathrm{S}=\frac{1}{\left[1+\frac{3.5 \mathrm{n}_{\mathrm{a}} \mathrm{h}}{\overline{\mathrm{V}}_{\mathrm{h}}}\right]\left[1+\frac{4 \mathrm{n}_{\mathrm{a}} \mathrm{b}}{\overline{\mathrm{V}}_{\mathrm{h}}}\right]} \\
& =\frac{1}{\left[1+\frac{3.5 \times 0.24 \times 104.2}{23.76}\right]\left[1+\frac{4 \times 0.24 \times 30.0}{23.76}\right]}=0.1061 \\
& E=\frac{0.47 \mathrm{~N}}{\left(2+N^{2}\right)^{5 / 6}}, N=\frac{n_{a} L_{h}}{\bar{V}_{h}}, L_{h}=1000\left(\frac{h}{10}\right)^{0.25} \\
& \mathrm{~L}_{\mathrm{h}}=1000\left(\frac{104.6}{10}\right)^{0.25}=1798 \\
& \mathrm{~N}=\frac{0.236 \times 1798}{23.76}=17.8221 \\
& E=\frac{0.47 \times 17.82}{\left(2+17.82^{2}\right)^{5 / 6}}=0.0685 \\
& \zeta=0.01 \\
& B=\frac{1}{1+\frac{\sqrt{36 h^{2}+64 b^{2}}}{L_{h}}} \\
& =\frac{1}{1+\frac{\sqrt{36 \times 104.2^{2}+64 \times 30.0^{2}}}{1798.39}}=0.728
\end{aligned}
$$

$$
\begin{gathered}
w=\frac{g_{v} r \sqrt{B}}{4}=\frac{3.7 \times 0.332 \times \sqrt{0.728}}{4}=0.262 \\
G=1+0.332\left(3.7^{2} \times 0.728 \times(1+0.262)^{2}\right. \\
\left.+\frac{3.67^{2} \times 0.1061 \times 0.0685}{0.01}\right)^{1 / 2}
\end{gathered}
$$

$\underline{G=2.683}$

Lateral deflection at roof level $(\Delta)$ was obtained from the model considering the following load combination:

$1.0 \mathrm{~g}_{\mathrm{k}}+1.4 \mathrm{~W}_{\mathrm{k}}-\mathrm{pd}=1.0 \mathrm{~g}_{\mathrm{k}}+(1.4 \times 2.683 \times$ Average loads)

Where $G=$ gust factor $=2.683$

Along wind acceleration $\left(a_{\mathrm{a}}\right)$

$$
\begin{aligned}
a_{\mathrm{a}} & =\left(2 \pi \mathrm{n}_{\mathrm{a}}\right)^{2} \mathrm{~g}_{\mathrm{f}} \mathrm{r} \sqrt{\frac{\mathrm{SE}}{\zeta}} \Delta \\
\alpha_{\mathrm{a}} & =(2 \pi \times 0.24)^{2} \times 3.67 \times 0.332 \sqrt{\frac{0.1061 \times 0.0685}{0.01}} \times .084 \\
& =\underline{0.1905 \mathrm{~m} / \mathrm{s}^{2}}
\end{aligned}
$$

\section{Calculation of wind loads on the building}

$\overline{\mathrm{F}}_{\mathrm{z}}=\mathrm{C}_{\mathrm{p}, \mathrm{e}} \overline{\mathrm{q}}_{\mathrm{z}} \mathrm{A}_{\mathrm{z}}$

$C_{p, e}$ for windward wall $=0.8$

$C_{p, c}$ for leeward wall $=-0.483$

Specimen calculation for $1^{\text {st }}$ floor level where $\mathrm{Z}=3.3 \mathrm{~m}$

$\overline{\mathrm{V}}_{\mathrm{z}}=\mathrm{V} \overline{\mathrm{M}}_{(\mathrm{z}, \mathrm{cat})} \mathrm{M}_{\mathrm{s}} \overline{\mathrm{M}}_{\mathrm{t}} \mathrm{M}_{\mathrm{i}}$

$\bar{V}_{z}=33.0 \times 0.38 \times 1.0 \times 1.0 \times 1.0=12.54 \mathrm{~m} / \mathrm{s}$

$\overline{\mathrm{q}}_{\mathrm{z}}=0.6 \overline{\mathrm{V}}_{\mathrm{z}}^{2} \times 10^{-3}=0.6 \times 12.54^{2} \times 10^{-3}=0.094 \mathrm{kPa}$

$\overline{\mathrm{F}}_{\mathrm{z}}=[(0.8)-(-0.483)] \times 0.094 \times(3.3 \times 1)=0.4 \mathrm{kN} / \mathrm{m}$

$\bar{F}_{z}$ is the wind load per linear meter along the horizontal direction of each floor level. Floor heights haven't mentioned in the following table as it vary from model to model. 
Table A.1 : Calculation of gust factor and along, wind acceleration

\begin{tabular}{|c|c|c|c|c|c|c|}
\hline Transfer floor level & $4^{\text {th }}$ & $6^{\text {th }}$ & $8^{\text {th }}$ & $10^{\text {th }}$ & $16^{\text {th }}$ & No TP \\
\hline$t$ & 4.243 & 4.081 & 3.936 & 3.815 & 3.660 & 4.442 \\
\hline$n_{\mathrm{a}}$ & 0.236 & 0.245 & 0.254 & 0.262 & 0.273 & 0.225 \\
\hline $\mathrm{g}_{\mathrm{v}}$ & 0.332 & 0.332 & 0.332 & 0.332 & 0.332 & 0.332 \\
\hline $\mathrm{g}_{\mathrm{f}}$ & 3.7 & 3.7 & 3.7 & 3.7 & 3.7 & 3.7 \\
\hline $\mathrm{V}_{\mathrm{h}}$ & 3.672 & 3.683 & 3.693 & 3.701 & 3.712 & 3.660 \\
\hline $\mathrm{h}$ & 23.76 & 23.76 & 23.76 & 23.76 & 23.76 & 23.76 \\
\hline $\mathrm{b}$ & 104.2 & 104.2 & 104.2 & 104.2 & 104.2 & 104.2 \\
\hline $\mathrm{S}$ & 30.0 & 30.0 & 30.0 & 30.0 & 30.0 & 30.0 \\
\hline $\mathrm{L}_{\mathrm{h}}$ & 0.106 & 0.101 & 0.096 & 0.092 & 0.087 & 0.113 \\
\hline $\mathrm{N}$ & 1797 & 1797 & 1797 & 1797 & 1797 & 1797 \\
\hline $\mathrm{E}$ & 17.82 & 18.53 & 19.21 & 19.82 & 20.66 & 17.02 \\
\hline $\mathrm{S}$ & 0.0685 & 0.0668 & 0.0652 & 0.0639 & 0.0622 & 0.0706 \\
\hline $\mathrm{B}$ & 0.01 & 0.01 & 0.01 & 0.01 & 0.01 & 0.01 \\
\hline $\mathrm{w}$ & 0.728 & 0.728 & 0.728 & 0.728 & 0.728 & 0.728 \\
\hline$\Delta$ & 0.262 & 0.262 & 0.262 & 0.262 & 0.262 & 0.262 \\
\hline Gust factor $(\mathrm{G})$ & 0.084 & 0.078 & 0.072 & 0.068 & 0.064 & 0.089 \\
\hline & 2.683 & 2.661 & 2.641 & 2.625 & 2.605 & 2.710 \\
\hline & 0.190 & 0.186 & 0.178 & 0.174 & 0.171 & 0.194 \\
\hline
\end{tabular}

Table A.2 : Wind loads at each floor level (in $\mathrm{kN} / \mathrm{m}$ )

\begin{tabular}{|c|c|c|c|c|c|c|}
\hline \multirow{2}{*}{ Level } & \multicolumn{7}{|c|}{$\bar{F}_{z}(\mathrm{kN} / \mathrm{m})$ for each model } \\
\cline { 2 - 7 } & No TP & 4 th & 6 th & $8^{\text {th }}$ & $10^{\text {th }}$ & $16^{\text {th }}$ \\
\hline$G$ & 0 & 0 & 0 & 0 & 0 & 0 \\
\hline 1 & 0.399 & 0.400 & 0.399 & 0.399 & 0.399 & 0.399 \\
\hline 2 & 0.443 & 0.440 & 0.443 & 0.443 & 0.443 & 0.443 \\
\hline 3 & 0.570 & 0.570 & 0.570 & 0.570 & 0.570 & 0.570 \\
\hline 4 & 0.690 & 0.690 & 0.690 & 0.690 & 0.690 & 0.690 \\
\hline 5 & 0.339 & 0.839 & 0.807 & 0.785 & 0.785 & 0.785 \\
\hline 6 & 0.848 & 0.848 & 0.930 & 0.848 & 0.848 & 0.848 \\
\hline 7 & 0.880 & 0.880 & 0.941 & 0.904 & 0.880 & 0.880 \\
\hline 8 & 0.946 & 0.946 & 0.946 & 1.038 & 0.946 & 0.946 \\
\hline 9 & 1.015 & 1.015 & 1.015 & 1.086 & 1.043 & 1.015 \\
\hline 10 & 1.051 & 1.051 & 1.051 & 1.051 & 1.153 & 1.051 \\
\hline 11 & 1.086 & 1.086 & 1.086 & 1.086 & 1.162 & 1.086 \\
\hline 12 & 1.123 & 1.123 & 1.123 & 1.123 & 1.123 & 1.123 \\
\hline 13 & 1.160 & 1.160 & 1.160 & 1.160 & 1.160 & 1.160 \\
\hline 14 & 1.198 & 1.198 & 1.198 & 1.198 & 1.198 & 1.198 \\
\hline 15 & 1.236 & 1.236 & 1.236 & 1.236 & 1.236 & 1.270 \\
\hline 16 & 1.236 & 1.236 & 1.236 & 1.236 & 1.236 & 1.356 \\
\hline 17 & 1.275 & 1.275 & 1.275 & 1.275 & 1.275 & 1.364 \\
\hline 18 & 1.315 & 1.315 & 1.315 & 1.315 & 1.315 & 1.315 \\
\hline 19 & 1.355 & 1.355 & 1.355 & 1.355 & 1.355 & 1.355 \\
\hline 20 & 1.355 & 1.355 & 1.355 & 1.355 & 1.355 & 1.355 \\
\hline 21 & 1.395 & 1.395 & 1.395 & 1.395 & 1.395 & 1.395 \\
\hline 22 & 1.437 & 1.437 & 1.437 & 1.437 & 1.437 & 1.437 \\
\hline 23 & 1.437 & 1.437 & 1.437 & 1.437 & 1.437 & 1.437 \\
\hline 24 & 1.479 & 1.479 & 1.479 & 1.479 & 1.479 & 1.479 \\
\hline 25 & 1.479 & 1.479 & 1.479 & 1.479 & 1.479 & 1.479 \\
\hline 26 & 1.521 & 1.521 & 1.521 & 1.521 & 1.521 & 1.521 \\
\hline 27 & 1.564 & 1.564 & 1.564 & 1.564 & 1.564 & 1.564 \\
\hline 28 & 1.564 & 1.564 & 1.564 & 1.564 & 1.564 & 1.564 \\
\hline 29 & 1.608 & 1.608 & 1.608 & 1.608 & 1.608 & 1.608 \\
\hline & & & & & & \\
\hline
\end{tabular}


Appendix A.2 Earthquake analysis

Static base shear calculation (According to AS 1170.4 - 1989)

For model where the transfer plate is at $4^{\text {th }}$ level, considering short term effects

$V=I\left(\frac{C S}{R_{f}}\right) G_{g}$

$C=\frac{1.25 a}{T^{2 / 3}}$

$\mathrm{T}_{1}=3.355 \mathrm{~s}$

$\mathrm{a}=0.15 \mathrm{~m} / \mathrm{s}^{2}$

$\mathrm{C}=0.0837$

$S=1.0$

$\mathrm{R}_{\mathrm{f}}=6.0$

$G_{g}=1.0 G_{k}+0.4 Q_{k}$

Where $I\left(\frac{2.5 a}{R_{f}}\right) G_{g} \geq V \geq 0.01 G_{g}$

$G_{g}=401645 \mathrm{kN}$ (From SAP2000 model)

$\mathrm{I}=1.0$

$V_{1}=I\left(\frac{0.0837 \times 1.0}{6.0}\right) 401645=\underline{\underline{5600 \mathrm{kN}}}$

Table A.3 : Calculation of static base shear for earthquake analysis

\begin{tabular}{|c|c|c|c|c|c|c|c|c|c|c|c|c|}
\hline Direction & \multicolumn{9}{|c|}{$x$ direction } & \multicolumn{6}{c|}{ y direction } \\
\hline Level & $4^{\text {th }}$ & $6^{\text {th }}$ & $8^{\text {th }}$ & $10^{\text {th }}$ & $16^{\text {th }}$ & No TP & $4^{\text {th }}$ & $6^{\text {th }}$ & $8^{\text {th }}$ & $10^{\text {th }}$ & $1^{\text {th }}$ & No TP \\
\hline $\mathrm{T}$ & 3.355 & 3.245 & 3.136 & 3.038 & 2.887 & 3.403 & 3.298 & 3.194 & 3.096 & 3.009 & 2.864 & 3.361 \\
\hline I & 1.0 & 1.0 & 1.0 & 1.0 & 1.0 & 1.0 & 1.0 & 1.0 & 1.0 & 1.0 & 1.0 & 1.0 \\
\hline $\mathrm{a}$ & 0.15 & 0.15 & 0.15 & 0.15 & 0.15 & 0.15 & 0.15 & 0.15 & 0.15 & 0.15 & 0.15 & 0.15 \\
\hline $\mathrm{C}$ & 0.0837 & 0.0856 & 0.0875 & 0.0894 & 0.0925 & 0.0829 & 0.0846 & 0.0864 & 0.0883 & 0.0900 & 0.0930 & 0.0836 \\
\hline $\mathrm{S}$ & 1.0 & 1.0 & 1.0 & 1.0 & 1.0 & 1.0 & 1.0 & 1.0 & 1.0 & 1.0 & 1.0 & 1.0 \\
\hline $\mathrm{Rf}$ & 6.0 & 6.0 & 6.0 & 6.0 & 6.0 & 6.0 & 6.0 & 6.0 & 6.0 & 6.0 & 6.0 & 6.0 \\
\hline $\mathrm{G}_{\mathrm{g}}(\mathrm{MN})$ & 401.6 & 367.8 & 313.9 & 302.8 & 199.7 & 359.9 & 401.6 & 367.8 & 313.9 & 302.8 & 199.7 & 359.9 \\
\hline $\mathrm{V}(\mathrm{kN})$ & 5600 & 5244 & 4579 & 4511 & 3078 & 4971 & 5665 & 5299 & 4618 & 4540 & 3094 & 5012 \\
\hline
\end{tabular}

